\title{
Sensitivity of Pyramidal Signs in Patients with Cervical Spondylotic Myelopathy
}

\author{
Hossam Elnoamany \\ Neurosurgical Department, Faculty of Medicine, Menoufia University Hospital, Menoufia University, Menoufia, Egypt
}

Asian Spine J 2016;10:65-9

http://dx.doi.org/10.4184/asj.2016.10.1.65

I am retracting our article "Sensitivity of Pyramidal Signs in Patients with Cervical Spondylotic Myelopathy" [1], because it was noted that several expressions of this article were identical to those of previously published paper without the proper citation "Eur Spine J 2010;19:1684-9" [2]. I deeply regret this plagiarism. I would like to express my most sincere apology to Prof. Chikuda and the European Spine Journal and to the Editor and readers of Asian Spine Journal.

\section{References}

1. Elnoamany H. Sensitivity of pyramidal signs in patients with cervical spondylotic myelopathy. Asian Spine J 2016; 10:65-9.

2. Chikuda H, Seichi A, Takeshita K, et al. Correlation between pyramidal signs and the severity of cervical myelopathy. Eur Spine J 2010;19:1684-9. 